\title{
Genetic, Environmental and Clinical Factors Related to Treatment Failure of Cervical Precancerous Lesions in a Cohort of Brazilian Women
}

\section{Ilce Ferreira da Silva ${ }^{1^{*}}$, Rosalina Jorge Koifman ${ }^{2}$, Virgílio Augusto Gomes Parreira ${ }^{3}$, Angélica Maria de Almeida Santos ${ }^{3}$ and Sergio Koifman ${ }^{2}$}

${ }^{1}$ Fernandes Figueiras Institute/Fiocruz, Av. Rui Barbosa, \#716, Flamengo, Rio de Janeiro, RJ, Brazil.

${ }^{2}$ National School of Public Health/Fiocruz, Rua Leopoldo Bulhões, \#1480,Manguinhos, Rio de Janeiro, RJ, Zip:21041-210, Brazil.

${ }^{3}$ Brazilian National Cancer Institute, Rua Equador, \#831, Santo Cristo, Rio de Janeiro, RJ, Zip:20220-410, Brazil.

\section{Authors' contributions}

This work was carried out in collaboration between all authors. Author IFS designed the study, performed the statistical analysis, wrote the protocol, and wrote the first draft of the manuscript. Authors RJK and SK managed the final approval of the manuscript, guaranteed the data security and evaluated the statistical analysis. Authors VAGP and AMAS managed the data collection and saw the patients. All authors read and approved the final manuscript.

Research Article

Received $1^{\text {st }}$ April 2013

Accepted 11 $1^{\text {th }}$ June 2013

Published 28 ${ }^{\text {th }}$ June 2013

\section{ABSTRACT}

Aims: To ascertain the risk of pre-cancerous treatment failure considering selected genetic, environmental, and clinical characteristics among Brazilian women.

Study Design: A prospective study developed in a cohort of women treated for Cervical Intraepithelial Neoplasia (CIN) lesion.

Place and Duration of Study: Gynecology Oncology day clinic of Brazilian National Cancer Institute, between October 2004 and May 2006.

Methodology: We included 285 women (age range 18-75 years) with CIN submitted to lesion excision. All patients were interviewed at admission to identify epidemiological and 
clinical characteristics, having blood samples collected, and a colposcopic examination performed. TP53 polymorphism was ascertained using PCR-RFLP. After treatment, the study population was followed up with Pap-tests during two years. Treatment failure was evaluated using histological confirmation of any altered tissue. Kaplan-Meyer curves and Cox Proportional Risk Model were used for data analysis.

Results: Frequencies of TP53 polymorphisms were: Arg72Pro genotype(Arg/Pro)177(62.1\%); Arg72 genotype(Arg/Arg)-55(19.3\%); Pro genotype (Pro/Pro)-53(18.6\%). Women with endocervical margins involvement showed an HR 7.01(1.73-28.44). Current smoking was statistically related to CIN treatment failure (HR.3.90,95\% Cl:1.28-11.91). Comparatively to $\mathrm{Arg} / \mathrm{Arg}$, the risks for treatment failure were: $\mathrm{HR} 1.51(95 \% \mathrm{Cl}: 0.23-9.80)$ for Arg/Pro women; and HR:1.41 (95\%Cl:0.31-6.52) for Pro/Pro.

Conclusion: Surgical margins involvement and current tobacco smoking presented independent risks for CIN treatment failure among the studied population. Pro/Pro genotype seems to be associated with CIN treatment failure.

Keywords: Cervical cancer; epidemiology; TP53 polymorphism; pre-cancer prognosis; tobacco smoking.

\section{INTRODUCTION}

Cervical cancer prevention is preventable through the detection and treatment of precancerous lesions, known as cervical intraepithelial neoplasia (CIN) [1]. Nevertheless, this neoplasia still accounts for the second most common cancer in women worldwide and the main cause of cancer-related mortality among women in developing countries [2]. An essential element in the prevention of cervical cancer is a safe and effective CIN treatment. However, a meta-analysis reported that the rate of post-treatment disease following excision methods is around $30 \%$ in developing countries [3]. This is particularly worrying as a large amount of these women will be screened just once in their lives, and treatment failure will charge them a very high risk of invasive disease [4]. Therefore, CIN treatment failure may substantially reduce the benefits of screening.

Several risk factors have been strongly associated to CIN treatment failure and most of them are also related to CIN development, such as age, tobacco smoking, persistent HPV infection [5], and genetic host factors such as TP53 polymorphism [1]. The TP53 gene encodes the p53 protein, which is involved in a series of pathways, such as apoptosis, transcription, DNA repair, maintenance of genomic stability, and cell cycle control [6]. Polymorphisms in the TP53 gene have been hypothesized to modify the conformations of the p53 protein, affecting the ability of HPV to bind and to degrade p53, thus potentially acting in early cervical carcinogenesis [7].

Polymorphism rs 1042522 at codon 72 of the TP53 has been investigated as a genetic cofactor since 1998, after HPV16E6 protein being reported to better degrade p53 protein containing arginine[G] at codon 72 than p53 containing proline[C] at that position[8]. Hence, homozygous women to Arginine allele would have a seven times higher risk for cervical cancer than those being heterozygous or homozygous to Proline allele [8].

More than 100 studies have been conducted aiming to investigate the role of polymorphism at codon 72 at TP53 gene on the risk of cervical cancer development, but showing inconsistent results [9]. Despite the fact that some researchers have studied p53 polymorphism as a prognostic marker in cervical cancer, these studies were developed 
among women with advanced cervical cancer [10], and none of them evaluated the effect of this polymorphism among women with precancerous lesion.

To our knowledge, no studies to date have evaluated TP53 polymorphism on precancerous lesion treatment failure, taking into account involvement of the margins, environmental and methodological factors, such as reliable exposure assessment, that have been also related to CIN treatment failure [11]. The present study was carried out aiming to address this gap towards ascertaining the risk of CIN treatment failure exploring the existing genetic (TP53 polymorphism at codon 72), environmental and clinical risk factors among Brazilian women.

\section{MATERIALS AND METHODS}

\subsection{Study Population and Design}

The characteristics of the study design have been previously described[12]. In short, the population study included 285 women enrolled among those attending a reference center of public health service providing free oncological care (INCA) in the city of Rio de Janeiro, Brazil. All gynecologic oncological outpatients showing altered Pap test results (CIN1, CIN2/3, but not invasive cervical cancer) from October 2004 to May 2006, were invited to participate if fulfilling the following criteria: age over 17 years old, no cervical treatment in the past 6 months before the study enrollment, no psychiatric diseases, no current pregnancy, having an intact uterus, and those agreeing to participate by signing an informed consent. The present study was approved by the Ethical Committee from Brazilian National Cancer Institute and from National School of Public Health, Brazil.

\subsubsection{Sample size estimation}

Considering that treatment failure incidence may vary between 5 to $35 \%$, in order to be conservative, we consider an incidence of treatment failure of $15 \%$ in the exposed group, and an expected difference between exposed and non-exposed group of 2.0 (OR=2.0), a sample of 279 women would be necessary to obtain statistically significant estimates (error $l=0,05$; power $=80 \%$ ).

\subsection{Clinical Procedures and Follow-Up}

After agreeing on signing the informed consent, all women were invited to answer a questionnaire with epidemiologic, environmental and clinical information applied by two trained registered nurses, and the patient was then submitted to a Colposcopy test. At colposcopy test, suspicious lesions were eligible to be totally extracted by LEEP. Those women with no visible lesion at colposcopic examination had another Pap test taken. If that cytology was altered those women were submitted to another colposcopic examination. In this second Colposcopy if there was a visible lesion, it was treated by LEEP; If there was no visible lesion, anendocervical curettage (ECC) was performed, in order to identify (and treat) the lesions that were in the endocervix, which is not completely visible at colposcopy. The date of a complete treatment (which means a complete lesion excision) was chosen as the startpoint of the study. After clinical examination and cervical biopsy, peripheral blood samples were obtained for single nucleotide polymorphism (SNP) tests.

According to the official Brazilian protocol for monitoring cytological abnormalities, all women receiving $\mathrm{CIN}$ treatment were monitored during the following two years, and a Pap smear 
exam should be carried out every 3 months on the first year, and every 6 months on the second year [13]. In order to guarantee patients compliance and the cytological alteration assessment, all women enrolled were followed-up during a two years period in prescheduled return visits. Pap smears were obtained and epidemiological variables (such as smoking status, parity, sexual behavior) were updated upon each visit. Referrals for colposcopy and colposcopic-directed punch biopsies were indicated for patients with persistent abnormal cytological findings. The patients with colposcopic-directed punch biopsies that revealed CIN1 or CIN2/3 lesions were either referred for repeated cone biopsy if fertility was to be preserved or for hysterectomy for women who had completed their family planning or had another gynecological indication (eg. menometrorrhagia). Follow-up length was either defined as the period of time that lapsed from the treatment (complete excision of the lesion) date until a confirmed diagnosis of treatment failure, or the last follow-up date in which participants showed no evidence of disease. Failure was defined as and altered Pap test with histological confirmation in the follow-up period, among those women with at least one normal Pap test between the treatment and the altered Pap test.

Those who missed appointments were contacted by phone and/or letter. These attempts at contacting subjects were repeated once a month until an appointment could be rescheduled or the woman explicitly stated that she wished to drop out of the study.

\subsection{Data Collection}

A longitudinal study involving repeated measurements was carried out recording the age at enrollment, skin color, sexual behavior, and reproductive history, history of sexually transmitted diseases, contraceptive use, smoking, and cervical outcome.

\subsubsection{Variables categorization}

Histological diagnosis was graded according to the Bethesda System [14] including condylomata and cervical intraepithelial neoplasia grades $\mathrm{I}(\mathrm{CIN}-1)$, and $\mathrm{CIN} 2-3 /$ in situ. Histological normal tissue presenting only reactive/reparative changes was categorized as negative(disease-free). Involvement of surgical margins was classified as clear(no margin involvement), ectocervix involvement only, or endocervix involvement. Cytological results were classified as Low grade Squamous Intraepithelial Lesion(LSIL) and as High grade Squamous Intraepithelial Lesion(HSIL).

Tobacco smoking was classified according to IARC definition [15] as current (over 100 cigarettes smoked in a lifetime), former smoker (quit smoking in the past 6 months at least) and non-smoker.

Oral contraceptive use was graded as current (regular use for at least a month by the time of enrollment), former (those who quit using for at least one month before the interview) and non-user. Ethnicity was classified as the self-reported skin color [16] and classified as white and non-white. All analyses were additionally stratified by age at first intercourse $(\leq 16$, and $>16$ years old), number of full-term pregnancies/parity ( $\leq 2$ and $>2)$, number of sexual partners $(1-2,3-4, \geq 5)$, a new partner during follow up ( 0 and $\geq 1)$, number of abortions in a lifetime $(0,1-2$, and $>2)$, and presence of sexually transmitted diseases at follow up (yes/no). Categorizations of these last variables were based on the mean and median split. 


\subsubsection{Outcome definitions}

The main outcome was histologically confirmed precancerous lesion or cancer diagnosed during the follow up visits.

\subsection{TP53Polymorphism Genotyping}

After DNA was extracted from leukocytes of peripheral blood through the salting procedure[17], genotyping for p53 polymorphism at codon 72 was carried out using a PCRRFLP based method[18]. The forward and reverse primers used for amplification of a 296bp fragment containing the polymorphic region were 5'- ATC TAC AGT CCC CCT TGC CG -3' and 5'- GCA ACT GAC CGT GCA AGT CA -3', respectively. Digestion with the restriction enzyme BstU1(New England Biolabs, Beverly, MA) was used to digest 5uL PCR product with overnight incubation at $60^{\circ} \mathrm{C}$. Bands of cut and uncut products were visualized on $3 \%$ agarose gels. The presence of the Arg allele was indicated by bands of $169 \mathrm{bp}$ and $127 \mathrm{bp}$, wherein no digestion of the Pro allele could be observed (Fig. 1).

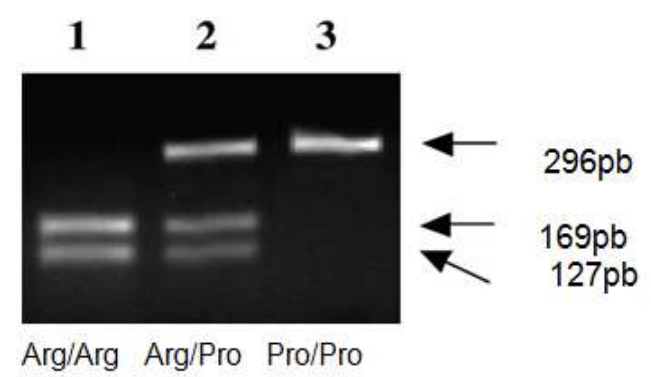

Fig. 1.Gel presenting the bands of TP53 polymorphism genotypes (1-Arg/Arg, 2Arg/Pro, 3-Pro/Pro) in three different DNA samples, using PCR-RFLP methods[12]

\subsection{Statistical Analysis}

Chi-square test was carried out to evaluate differences between the frequencies, considering a significant level of $5 \%$. Kaplan-Meier method was used to estimate cumulative risks of treatment failure, being compared using the Log-Rank test (Cl:95\%). A Cox proportional hazard regression analysis was performed to estimate the crude and adjusted hazard ratio $(\mathrm{HR})$ of treatment failure according to the different associated risk factors, considering a significance level of $5 \%$. All analysis was carried out using SPSS software package version 17.0 for windows (SPSS, IBM, Armonk, NY, USA).

\section{RESULTS}

According to Table 1, TP53 polymorphism was distributed as follows: $177(62.1 \%)$ women showing an Arg72Pro genotype (Arg/Pro), 55(19.3\%) homozygous for an Arg72 genotype (Arg/Arg), and 53(18.6\%) homozygous for a Pro72 genotype(Pro/Pro), which was in HardyWeinberg equilibrium. Around $47 \%$ women were under 30 years old, $69.1 \%$ were non-white, $75.4 \%$ had HSIL cytology at the beginning of the study, and $35.7 \%$ had margin involvement after treatment. The prevalence of current tobacco use was $28,1 \%$, and most of treatment failure were $\mathrm{CIN} 2 / 3(62,5 \%)$. 
Table 1. Environmental, clinical and genetic host factors distribution in the studied hospital cohort, Brazil

\begin{tabular}{|c|c|c|c|}
\hline Variable & Overall ${ }^{a}$ & $\%$ & (Cl: 95\%) \\
\hline TP53Polymorphism & $\mathbf{N}$ & & \\
\hline Pro/Pro & 53 & 18.6 & $(14.1-23.1)$ \\
\hline Arg/Pro & 177 & 62.1 & $(56.5-67.7)$ \\
\hline Arg/Arg & 55 & 19.3 & $(14.7-23.9)$ \\
\hline \multicolumn{4}{|l|}{ Age (years) } \\
\hline $18-30$ & 134 & 47.0 & $(41.2-52.8)$ \\
\hline $31-45$ & 95 & 33.3 & $(27.9-38.8)$ \\
\hline$\geq 45$ & 56 & 19.6 & $(15.0-24.3)$ \\
\hline \multicolumn{4}{|l|}{ Ethñicity (skin color) } \\
\hline White & 88 & 30.9 & $(25.5-36.2)$ \\
\hline Non-white & 197 & 69.7 & $(63.4-74.4)$ \\
\hline \multicolumn{4}{|l|}{ Sexual onset (years) } \\
\hline$\leq 16$ & 145 & 49.1 & $(45.1-56.7)$ \\
\hline$>16$ & 140 & 40.9 & $(43.3-54.9)$ \\
\hline \multicolumn{4}{|l|}{ Abortion } \\
\hline 0 & 156 & 54.7 & $(49.0-60.5)$ \\
\hline 1 to 2 & 110 & 38.6 & $(32.9-44.2)$ \\
\hline$>2$ & 19 & 6,7 & $(3.8-9.6)$ \\
\hline \multicolumn{4}{|l|}{ Margin involvement } \\
\hline Clear & 153 & 64.3 & $(59.3-71.5)$ \\
\hline Ectocervix & 43 & 18.7 & $(13.4-23.3)$ \\
\hline Endocervix ${ }^{c}$ & 38 & 15.9 & $(11.5-21.0)$ \\
\hline \multicolumn{4}{|l|}{ Tobacco use } \\
\hline Never & 144 & 50.5 & $(44.7-56.3)$ \\
\hline Former & 61 & 21.4 & $(15.6-26.2)$ \\
\hline Current & 80 & 28.1 & $(22.9-33.3)$ \\
\hline \multicolumn{4}{|l|}{ Sexual partners } \\
\hline $1-2$ & 96 & 33.7 & $(28.2-39.2)$ \\
\hline $3-4$ & 88 & 30.9 & $(25.5-36.2)$ \\
\hline$\geq 5$ & 101 & 35.4 & $(29.9-41.0)$ \\
\hline \multicolumn{4}{|c|}{ Oral contraceptive use } \\
\hline Never & 44 & 15.4 & $(11.2-19.6)$ \\
\hline Former & 66 & 23.2 & $(18.3-28.1)$ \\
\hline Current & 175 & 61.4 & $(55.8-67.1)$ \\
\hline \multicolumn{4}{|c|}{ Duration of oral contraceptive use ${ }^{\mathrm{b}}$} \\
\hline$\leq 77$ months & 127 & 53.1 & $(46.8-59.5)$ \\
\hline & 112 & 46.9 & $(40.5-53.2)$ \\
\hline \multicolumn{4}{|c|}{ Duration of tobacco smoking ${ }^{b}$} \\
\hline$\leq 10$ years & 44 & 31.2 & $(23.6-38.9)$ \\
\hline$>10$ years & 97 & 68.8 & $(61.1-76.4)$ \\
\hline \multicolumn{4}{|l|}{ Cytology at entrance } \\
\hline LSIL & 66 & 25,6 & $(18.3-28.1)$ \\
\hline HSIL & 215 & 75.4 & $(70.4-80.4 .4)$ \\
\hline Cancer & 04 & 1.4 & $(-)$ \\
\hline
\end{tabular}




\begin{tabular}{lllll} 
Histology at treatment & & & \\
CIN 1 & 129 & 45.3 & $(39.5$ & $-51.0)$ \\
CIN 2-3 & 156 & 54.8 & $(49.0$ & $-60.5)$ \\
Treatment Failure & & & & \\
CIN 1 & 4 & 25.0 & $(-)$ \\
CIN 2/3 & 10 & 62.5 & $(-)$ \\
Cancer & 2 & 12.5 & $(-)$ \\
\hline${ }^{a}$ Total may vary according to missing values; ${ }^{2}$ Analysis carried out among former and current users, only. ${ }^{c}$ This \\
$\quad$ category includes endocervical margin involvement and both margins involvement.
\end{tabular}

In Table 2 we observed that women more likely to present treatment failure in 24 months were those who were current tobacco users $(12,9 \%, \mathrm{p}=.0176)$; CIN 2/3 histological result at the follow-up startpoint $(7,8 \%, p=.0247)$; and having ectocervix $(9,8 \%)$ or endocervix $(14,7 \%)$ margin involvement $(p=.0017)$.

Table 2. Probability of CIN treatment failure, studied hospital cohort $(n=285)$, Rio de Janeiro, Brazil, 2004-2008

\begin{tabular}{|c|c|c|}
\hline \multirow[t]{2}{*}{ Variable } & \multicolumn{2}{|c|}{ \% Treatment failure } \\
\hline & 24 months & ${ }^{b}$ Log-Rank test: $95 \%$ \\
\hline \multicolumn{3}{|c|}{ TP53 Polymorphism } \\
\hline Arg/Arg & 6.0 & \\
\hline Arg/Pro & 6.8 & 0.7433 \\
\hline Pro/Pro & 6.2 & \\
\hline \multicolumn{3}{|l|}{ Age } \\
\hline $18-30$ & 11.9 & \\
\hline $31-45$ & 6.7 & 0.6855 \\
\hline$>45$ & 7.5 & \\
\hline \multicolumn{3}{|l|}{ Skin color } \\
\hline White & 21 & \\
\hline Non-white & 4.6 & 0.037 \\
\hline \multicolumn{3}{|c|}{ Oral contraceptive use } \\
\hline Never & 3.1 & \\
\hline Former & 13.5 & 0.1006 \\
\hline Current & 11.5 & \\
\hline \multicolumn{3}{|c|}{ Duration of contraceptive use $\mathrm{a}^{\mathrm{a}}$} \\
\hline$<77$ months & 4.2 & 0.3375 \\
\hline$>77$ months & 7.5 & \\
\hline \multicolumn{3}{|l|}{ Tobacco use } \\
\hline Never & 4.7 & \\
\hline Former & 3.7 & 0.0176 \\
\hline \multirow{2}{*}{\multicolumn{3}{|c|}{ Duration of tobacco use ${ }^{a}$}} \\
\hline & & \\
\hline$\leq 10$ years & 4.6 & 0.2438 \\
\hline$>10$ years & 10.9 & \\
\hline \multicolumn{3}{|l|}{ Histology } \\
\hline CIN-1 & 3.6 & 0.0247 \\
\hline CIN 2-3 & 7.8 & \\
\hline \multicolumn{3}{|c|}{ Margin involvement } \\
\hline Clear & 3.1 & \\
\hline Ectocervix & 9.8 & 0.0017 \\
\hline Endocervix ${ }^{c}$ & 14.7 & \\
\hline
\end{tabular}




\section{Menarche}
$>13$ years old
5.2
0.9077
$\leq 13$ years old
6.1
7.1
$>16$ years old
4.6
$\leq 16$ years old
1
0.2380

Years from menarche to sexual onset

\begin{tabular}{lll}
$>3$ & 6.3 & 0.5355 \\
$\leq 3$ & 5.4 & \\
\hline $\begin{array}{l}\text { xual partners } \\
1-2\end{array}$ & 4.5 & \\
$3-4$ & 4.9 & 0.1688 \\
$\geq 5$ & 10,4 & \\
ortion & & \\
0 & 13.0 & 0.1549 \\
1 to 2 & 8,4 & \\
$>2$ & 19,8 & 0.3356 \\
$\leq 2$ & &
\end{tabular}

${ }^{a}$ Analysis carried out among former and current users, only. ${ }^{b}$ Log-Rank test obtained from KaplanMeier analysis. ${ }^{c}$ This category includes endocervical margin involvement and both margins involvement.

Margin involvement was an independent risk factor for CIN treatment failure, ( $\mathrm{HR}=7.01 ; 95 \% \mathrm{Cl}: 1.73-28.4)$. Current tobacco use was also an independent risk factor for $\mathrm{CIN}$ treatment failure $(\mathrm{HR}=3.90 ; \mathrm{Cl}: 95 \%=1.28-11.91)$. Comparatively to $\mathrm{CIN} 1$ women at the follow-up startpoint, women with CIN2/3 histological result showed an $\mathrm{HR}=4.67(95 \% \mathrm{Cl}: 1.27$ 17.05)(Table 3). The joint effect of tobacco smoking and TP53 polymorphism in the risk of treatment failure was explored, but no statistical significance was found.

Table 3.Crude and adjusted HR for CIN treatment failure among Brazilian Women, Rio de Janeiro (2004-2008)

\begin{tabular}{|c|c|c|}
\hline \multirow[t]{2}{*}{ Variables } & \multicolumn{2}{|c|}{ Treatment failure in 24 months } \\
\hline & Crude HR (Cl:95\%) & ${ }^{\text {a } a d j u s t e d ~}$ \\
\hline \multicolumn{3}{|l|}{ TP53 Polymorphism } \\
\hline Arg/Arg & 1 & 1 \\
\hline Arg/Pro & $1.63(0.27-9.77)$ & $1.51(0.23-9.80)$ \\
\hline Pro/Pro & $1.79(0.40-8.10)$ & $1.41(0.31-6.52)$ \\
\hline \multicolumn{3}{|l|}{ Age (years) } \\
\hline $18-30$ & 1 & 1 \\
\hline $31-45$ & $1.43(0.46-4.45)$ & $1.77(0.56-5.59)$ \\
\hline$>45$ & $1.69(0.45-6.02)$ & $1.89(0.52-6.82)$ \\
\hline \multicolumn{3}{|l|}{ Ethnicity } \\
\hline White & 1 & 1 \\
\hline \multirow{2}{*}{\multicolumn{3}{|c|}{ Margin Involvement }} \\
\hline & & \\
\hline Clear & 1 & 1 \\
\hline $\begin{array}{l}\text { Ectocervix } \\
\text { Endocervix }^{c}\end{array}$ & $\begin{array}{l}3.44(0.69-17.08) \\
\mathbf{8 . 6 0}(\mathbf{2 . 1 5}-\mathbf{3 4 . 4 1})\end{array}$ & $\begin{array}{l}3.81(0.76-19.08) \\
7.01(1.73-\mathbf{2 8 . 4 4})\end{array}$ \\
\hline
\end{tabular}


Tobacco use

Never

Former

Current

Sexual partners

$$
1-2
$$

$3-4$

$\geq 5$

\section{Oral contraceptive use}

Never

Former

Current

Duration of OC use

$\leq 77$ months

$>77$ months

Duration of tobacco use ${ }^{\mathrm{b}}$

$\leq 10$ years

Histology

$>10$ years

Abortion

CIN-1

CIN 2-3

1 to 2

$>2$
1

$0.90(0.18-4.67) \quad 0.81(0.15-4.35)$

$3.68(1.23-10.97) \quad 3.90(1.28-11.91)$

1

$1.44(0.32-6.45) \quad 1.62(0.36-7.38)$

$2.98(0.81-11.00) \quad 2.77(0.75-10.24)$

1

$3.02(0.97-9.40) \quad 3.03(0.94-9.73)$

$2.68(0.75-9.52) \quad 3.16(0.86-11.57)$

1

$1.74(0.55-5.49) \quad 1.96(0.60-6.38)$

1

$2.43(0.52-11.31) \quad 2.90(0.51-16.52)$

1

$3.81(1.10-13.37) \quad 4.67(1.27-17.05)$

1

$1.68(0.57-5.01) \quad 1.31(0.43-4.00)$

$3.68(0.91-14.82) \quad 2.85(0.66-12.23)$

${ }^{a} H R$ adjusted by age and ethnicity; ${ }^{b}$ Analysis carried out among former and current users, only. ${ }^{c}$ This category includes endocervical margin involvement and both margins involvement.

\section{DISCUSSION}

Recently, two meta-analyses were carried out aiming to investigate the role of TP53 polymorphism on the risk of cervical cancer. The first one analyzed individual data from 49 different studies worldwide and no association was found when the analysis was restricted to methodologically sound studies [19]. The second reanalyzed 45 studies of the above metaanalysis and found substantial heterogeneity between the estimates from the studies. This was attributable to study populations with genotypic distributions that departed from HardyWeimberg equilibrium and may suggest problems with genotyping/laboratory methods or study design [20].

While this inconsistency across studies might reflect a lack of true association, it is also plausible that some of the heterogeneity may be either due to differential haplotipic structure of TP53 codon 72 polymorphisms in different study population with different backgrounds[21], or due to variations between countries in the association between TP53 codon 72 polymorphism and cervical cancer, with some countries showing a trend toward increased risk of cervical cancer associated with proline at codon $72[22,23]$.

Although Arg/Arg genotype is known as being more susceptible to the effects of HPV E6 than the Pro/Pro, increasing the risk of cervical cancer development [8], it doesn't seem to play the same role in the risk of CIN treatment failure, since the present study results suggest that proline at codon 72 , but not arginine, was associated with CIN treatment failure, despite lacking statistical significance. Thus, the role of p53 72 polymorphism on CIN treatment failure remains unknown, since HPV infection and its persistence are known as 
the main risk factors related to treatment failure [1] and clearance rate of HPV infection after CIN treatment ranges from $82.3 \%-92.2 \%[5]$.

One possible explanation is that after CIN treatment with LEEP, the role of $\mathrm{Arg} / \mathrm{Arg}$ genotype(apoptosis) might be more efficient in preventing treatment failure than either observed with Pro/Pro(G1 arrest), or Arg/Pro genotypes [23]. Bhattacharya and colleagues [11] reported that proline at codon 72 probably facilitates HPV-16/18-induced transformation of cervical cells by affecting cell cycle regulation. Moreover, the ability of HPV to avoid immune attack might be associated with the transforming potential of the virus. Thus, these authors showed that women who were HLA-B*07 and Pro/Pro carriers were at higher risk of cervical cancer development when compared to non-carriers of both alleles (OR=14.05, $\mathrm{Cl}: 95 \% 1.11-177.30)$.

It still remains unclear how different patterns of tobacco use and its relationship with other risk factors affect a woman's risk of developing cancer and/or CIN treatment failure. Our results provide evidence that current smokers, compared to non-smokers, are likely to present CIN treatment failure(Tables 2 and 3). If confirmed by other studies, such observation can be translated into important public health intervention policies towards smoking control among women with CIN lesions.

A large prospective study in UK exploring the role of HPV testing and smoking on CIN treatment failure found that smoking is an independent risk factor for CIN treatment failure. This study results showed that the OR of treatment failure of CIN increases by a factor of 2.58 (95\% C.I. 1.7-3.91) for each additional 10 cigarettes a women smokes daily(ranging 0 30 cigarettes), having this risk indeed persisted after HPV adjustment [24]. The authors suggested that this increased risk estimate may result from a local immunological effect of smoking on the cervical epithelium, or by the formation of carcinogen-DNA adducts in the cervical tissue itself, which may initiate neoplastic transformation [24].

Another important finding was that the histologic lesion CIN 2-3 at treatment significantly increased the risk of treatment failure, comparing to $\mathrm{CIN}-1$ (Table 2 and 3). This might be explained by the fact that CIN 2-3 are related to high-risk HPV (HR-HPV) infection which is more likely to persist and has been found as one of the main risk factor related to CIN treatment failure $[24,25]$. In the same way, the number of sexual partners presented a doseresponse relationship and a strong association with treatment failure (Table 2 and 3), although no statistical significance was found. Number of sexual partner is closely related to HPV infection, since the more sexual partner a woman has the more likely of achieving an HPV infection. Kreimer et al [25] developed a cohort study in USA with a group of women with ASCUS-LSIL. The authors found that HPV infection detected 6 months after treatment may predict $\mathrm{CIN}$ development after treatment.

A limitation of the present study was that HPV status could not be ascertained. However, this study tried to deal with that issue through stratification by the number of sexual partners and the involvement of margins, whose occurrence suggests persistence of residual disease.

Our findings provide evidence that women with margins involvement were significantly at higher risk of CIN treatment failure when compared to those with clear margins, regardless of age and ethnicity. Our results are also in agreement with other studies, which reported that the depth of treatment and the completeness of excision are the crucial treatment factors determining a successful outcome[3,26]. As the depth of treatment is dependent on the extent of involvement of the endocervical canal, it is very important to accurately identify 
the location of the squamocolumnar junction. The mentioned authors also advocate that when the CIN 2-3 is present at the deep margins, there will be a risk that any residual disease may be an undetected invasive lesion.

It has been suggested that besides environmental and genetic host characteristics, the risk of CIN treatment failure is closely related to clinical conditions, such as the presence of residual disease (surgical margin status) and surgeon's expertise [26]. One of the strengths of our study is that surgical procedures (LEEP) were accomplished by only two oncological gynecology surgeons aiming to assure quality of treatment. Since the study population consisted of women with pre-cancer lesion who underwent conservative treatment, and therefore, all of them were at the risk set of presenting the studied outcome (CIN treatment failure), it is improbable that selection bias has occurred, and external validity was provided.

\section{CONCLUSION}

This study provides evidence that obtaining clear margins particularly clear deep margins (endocervix), when treating CIN is very important to prevent treatment failure, independently of ethnicity and age at the treatment. Moreover, the study pointed out that current tobacco smoking was strongly associated to CIN treatment failure. Thus, women should be more aware of the risks of smoking, and smokers should be encouraged to stop smoking any time before/after CIN treatment.

The present study is the first one which investigated prospectively the relationships between p53 polymorphisms and tobacco smoking on CIN treatment failure among Brazilian women, and the presented results need further confirmation by other investigations.

\section{CONSENT}

Authors declare that all study participants signed a written informed consent.

\section{ETHICAL APPROVAL}

The present study was approved by the Ethical Committee of both the Brazilian National Cancer Institute and the National School of Public Health. All authors declare that written informed consent was obtained from all patients enrolled in this study.

\section{ACKNOWLEDGEMENTS}

This study was partially supported by the Ministry of Health and The Brazilian National Research Council (CNPq), which provided the source of molecular analysis. Authors also thanks to Amy Fairchild, Jeremy Conrad and Anelise Gondar for the English text review. Special thanks to Michelle de Oliveira e Silva for the standardization of molecular analysis procedures.

\section{COMPETING INTERESTS}

The authors declare no conflict of interest. 


\section{REFERENCES}

1. International Agency for Research on Cancer. Human Papillomaviruses. IARC Monogr Eval Carcinog Risks Hum, vol 90. Published 2007. Accessed 02 January 2013. Available: http://monographs.iarc.fr/ENG/Monographs/vol90/index.php.

2. Ferlay J, Shin HR, Bray F, Forman D, Mathers C, Parking DM. GLOBOCAN 2008 V2.0, Cancer incidence and mortality worldwide. IARC CancerBase No. 10 [internet]. Lyon, France: International Agency for Research on Cancer; 2010. Accessed 20 December 2012. Available: http://globocan.iarc.fr.

3. Ghaem-Maghami S, Sagi S, Majeed G, Soutter WP. Incomplete excision of cervical Intraepithelial neoplasia and risk of treatment failure: a meta-analysis. Lancet Oncol. 2007;8(11):985-93. PMID:17928267.

4. Silva IF, Koifman RJ, Mattos IE. Epidemiological characteristics related to treatment failure of preinvasive cervical intraepithelial neoplasia among Brazilian women. Intl J Gynecol Cancer. 2009;19(8):1427-31. doi: 10.1111/IGC.0b013e3181b8677f.

5. Aerssens A, Claeys $P$, Garcia A, Sturtewagen $Y$, Velasquez R, Vanden Broeck D, et al. Natural history and clearance of HPV after treatment of precancerous cervical lesions. Histopathology.2008;52(3):381-86. doi: 10.1111/j.1365-2559.2007.02956.x.

6. Hussain SP, Harris CC. p53 biological network: at the crossroads of the cellular-stress response pathway and molecular carcinogenesis.J Nihon Med Sch.2006;73(2):54-64. PMID: 16641528.Review.

7. Koshiol J, Lindsay L, Pimenta JM, Poole C, Jenkins D, Smith JS. Persistent Human Papillomavirus Infection and Cervical Neoplasia: A Systematic Review and MetaAnalysis. Am J Epidemiol. 2008;168:123-137. doi: 10.1093/aje/kwn036. Epub 2008 May 15. Review.

8. Storey A, Thomas M, Kalita A, Harwood C, Gardiol D, Mantovani F., et al. P53 polymorphism in the development of human papillomavirus-associated cancer. Nature. 1998;393(6682):229-34. PMID: 9607760.

9. Habbous S, Pang V, Eng L, Xu W, Kurtz G, Liu FF, et al. P53 Arg72Pro Polymorphism, HPV status and initiation, Progression, and development of cervical cancer: A systematic review and Meta-Analysis. Clin Cancer Res. 2012;18(23):640715. doi: 10.1158/1078-0432.CCR-12-1983. Epub 2012 Oct 12.

10. Lu X, Feki A. Phenotypic features with p53 alterations related to human papillomavirus and prognostic evaluation in cervical cancer. Int J Gynecol_Cancer. 2006;16(2):70817. PMID: 16681751.

11. Bhattacharya P, Sengupta S. Predisposition to HPV 16/18-related cervical cancer because of proline homozygosity at codon 72 of p53 among Indian women is influenced by $\mathrm{HLA}-\mathrm{B}^{*} 07$ and homozygosity of HLA-DQB ${ }^{*} 03$. Tissue Antigens.2007;70(4):283-93. PMID: 17767549

12. Ferreira da Silva I, Koifman RJ, Quinto Santos Souza C, Ferreira de Almeida Neto O, Koifman S. TP53 genetic polymorphisms and environmental risk factors associated with cervical carcinogenesis in a cohort of Brazilian women with cervical lesions. J Toxicol Environ Health $A$. 2010;73(13-14):888-900. doi: $10.1080 / 15287391003744823$. 
13. Ministry of Health. Brazilian National Cancer Institute. Coordination of Surveillance and prevention. Brazilian Nomenclature for cervical report and standardized procedures: Recommendations for health professionals. Second Edition, 2006. Accessed $02 \quad$ January 2013.2 Available: http://www1.inca.gov.br/inca/Arquivos/Titulos/Nomenclatura colo do utero.pdf. Portuguese.

14. Solomon D, Davey D, Kurman R, Moriarty A, O'Connor D, Prey M. The 2001 Bethesda System: Terminology for Reporting Results of Cervical Cytology. Journal of the American Medical Association. 2002;287(16):2114-2119. PMID: 11966386.

15. International Agency for Research on Cancer. 2004. Tobacco Smoke and involuntary smoking. IARC Monogr Eval Carcinog Risks Hum. 2004;83. Accessed 02 January 2013. Available: http://www.monographs.iarc.fr/ENG/Monographs/vol38/volume38.pdf.

16. Instituto Brasileiro de Geografia e Estatística. National research by household sample. Methodology Notes; 2009. Accessed 02 January 2013. Available: http://www.ibge.gov.br/home/estatistica/populacao/trabalhoerendimento/pnad2009/pn ad sintese 2009.pdf. Portuguese

17. Miller AS, Dykes DD, Polesky HF. A simple procedure for extracting DNA from human nucleated cells. Nucleic Acid Res.1988;16:215. PMID: 3344216.

18. Lee J, Lee Y, Yang S, Shi W, Luh S, Chen C, et al. Genetics polymorphisms of p53 and GSTP1, but not NAT2, are associated with suscetibility to squamous cell carcinoma of the esophagus. Int $\mathrm{J}$ Cancer (Pred Oncol). 2000;89:454-58. PMID: 11008209.

19. Klug SJ, Ressing M, Koenig J, Abba MC, Agorastos T, Brenna SM, et al. TP53 codon 72 polymorphism and cervical cancer: a pooled analysis of individual data from 49 studies.Lancet Oncol. 2009;10(8):772-84. doi: 10.1016/S1470-2045(09)70187-1. Epub 2009 Jul 20.

20. Koushik A, Platt RW, Franco EL. p53 codon 72 polymorphism and cervical neoplasia: a meta-analysis review. Cancer Epidemiol Biomarkers Prev. 2004;13(1):11-22. PMID: 16721787

21. Koshiol J, Hildesheim A, Gonzalez P, Bratti MC, Porras C, Schiffman M, et al. Common genetic variation in TP53 and risk of human papillomavirus persistence and progression to $\mathrm{CIN} 3 /$ cancer revisited. Cancer Epidemiol Biomarkers Prev. 2009;18(5):1631-7. doi: 10.1158/1055-9965.EPI-08-0830.

22. Sousa $H$, Santos AM, Pinto D, Medeiros R. Is the p53 codon 72 polymorphism a key biomarker for cervical cancer development? A meta-analysis review within European populations. Int J Mol Med. 2007;20(5):731-41. PMID: 17912468

23. Bojesen SE, Nordestgaard BG. The common germline Arg72Pro polymorphism of p53 and increased longevity in humans. Cell Cycle.2008;7(2):158-63. PMID: 18256523.

24. Acladious NN, Sutton C, Mandal D, Hopkins R, Zaklama M, Kitchener H. Persistent human papillomavirus infection and smoking increase risk of failure of treatment of cervical intraepithelial neoplasia (CIN). Int J Cancer. 2002;20;98(3):435-9. PMID: 11920596.

25. Kreimer AR, Guido RS, Solomon D, Schiffman M, Wacholder S, Jeronimo J, Wheeler $\mathrm{CM}$, Castle PE. Human papillomavirus testing following loop electrosurgical excision procedure identifies women at risk for posttreatment cervical intraepithelial neoplasia grade 2 or 3 disease. Cancer Epidemiol Biomarkers Prev. 2006;15(5):908-14. PMID: 16702369. 
26. Ghaem-Maghami S, De-Silva D, Tipples M, Lam S, Perryman K, Soutter W. Determinants of success in treating cervical intraepithelial neoplasia. BJOG. 2011;118(6):679-84. doi: 10.1111/j.1471-0528.2010.02770.x. Epub 2010 Nov 18.

(C) 2013 da Silva et al.; This is an Open Access article distributed under the terms of the Creative Commons Attribution License (http://creativecommons.org/licenses/by/3.0), which permits unrestricted use, distribution, and reproduction in any medium, provided the original work is properly cited.

Peer-review history:

The peer review history for this paper can be accessed here: http://www.sciencedomain.org/review-history.php?iid=205\&id=12\&aid=1566 